\title{
Endovascular flexible stent grafting with arch vessel bypass for a case of aortic arch aneurysm
}

Yoshio Nitta, MD, PhD, Yusuke Tsuru, MD, PhD, Kazuhiro Yamaya, MD, Junetsu Akasaka, MD, PhD, Katsuhiko Oda, MD, PhD, and Koichi Tabayashi, MD, PhD, Sendai, Japan

See related articles on pages 1181 and 1184 .

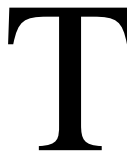

he Matsui-Kitamura (MK) stent graft (Kitagawa, Kanazawa, Japan) is designed to fit the curvy portions of the aorta because first-generation rigid skeleton-type stent grafts potentially cause kinking and endoleak as a result of limited flexibility. ${ }^{1-3}$ The MK stent graft consists of a custom-made, self-expandable spiral mesh of a single nitinol wire and thin-walled polyester fabric. We report the first surgical case of aortic arch aneurysm treated with this flexible and curved stent

From the Department of Cardiothoracic Surgery, Tohoku University Graduate School of Medicine, Sendai, Japan.

Received for publication April 16, 2003; accepted for publication April 29, 2003.

Address for reprints: Yoshio Nitta, MD, PhD, Department of Cardiothoracic Surgery, Tohoku University Graduate School of Medicine, 1-1, Seiryou-cho, Aoba-ku, Sendai, Japan 980-8575 (E-mail: ynitta@mail.cc. tohoku.ac.jp).

J Thorac Cardiovasc Surg 2003;126:1186-8

Copyright $\odot 2003$ by The American Association for Thoracic Surgery $0022-5223 / 2003 \$ 30.00+0$

doi:10.1016/S0022-5223(03)00934-6 graft after extra-anatomic bypass of the arch vessels ${ }^{4}$ to prepare a landing zone for the stent graft.

\section{Clinical Summary}

A 71-year-old man with distal arch aortic aneurysm diagnosed 2 months before in another hospital was referred to our hospital because blood-streaked sputum occurred gradually. Hypertension and severe chronic renal failure were also present. Magnetic resonance imaging revealed that the enlarged saccular-type aneurysm was pressing the lung, and this pressure was assumed to have caused the lung injury (Figure 1,A). The size and shape of the aorta were evaluated, and a suitable MK stent graft was ordered immediately.

After achievement of general anesthesia, 3 Dacron conduits with diameters of $8 \mathrm{~mm}$ were anastomosed to the right femoral and bilateral subclavian arteries. During these anastomoses, another straight conduit was anastomosed to a side of a Dacron Y graft (proximal diameter, $16 \mathrm{~mm}$ ) to make the outflow tract of the graft triple. After median sternotomy, left heart bypass was established with the right upper pulmonary vein drainage cannula and bilateral subclavian arterial conduits. The patient was heparinized moderately before these cannulations, and the activated coagulation time was kept between 200 and 250 seconds. Left heart bypass was switched to antegrade selective cerebral perfusion (SCP) by placing clamps on 3 arch vessels and inserting an additional arterial cannula to the left common carotid artery (Figure 2, A). The arch

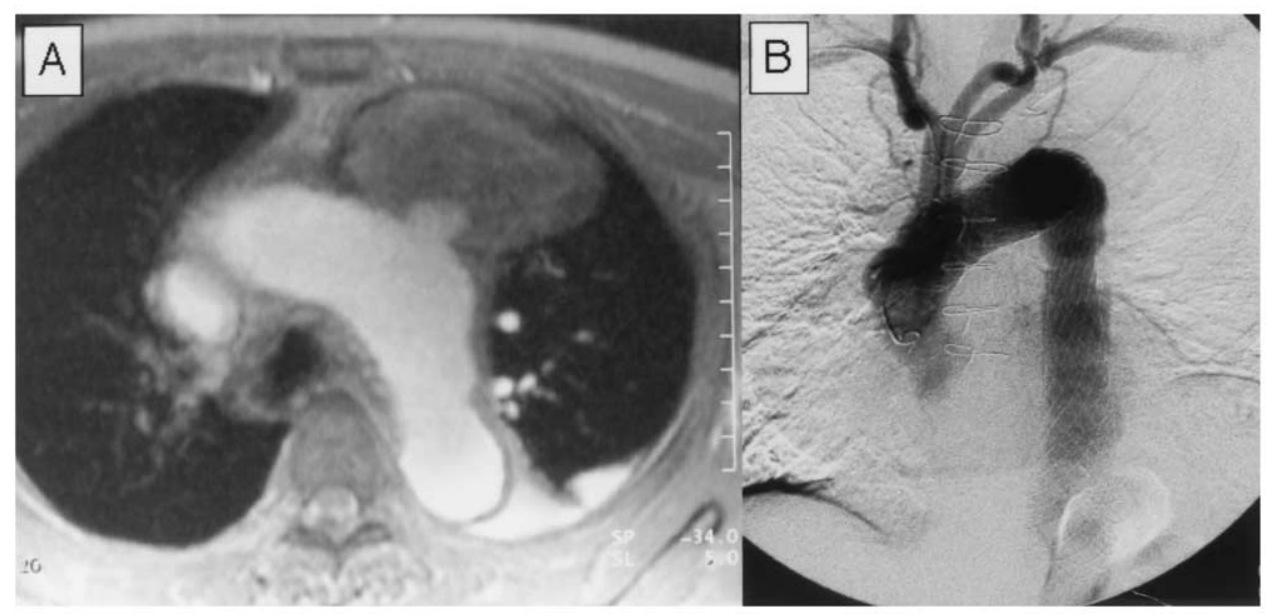

Figure 1. Preoperative magnetic resonance imaging (A) showed an extended saccular-type aortic arch aneurysm. Postoperative angiography (B) showed no endoleak around the MK stent graft that was inserted into the aortic arch. Stumps of the arch vessels were closed, and blood flows were restored through extra-anatomic bypass grafts. 

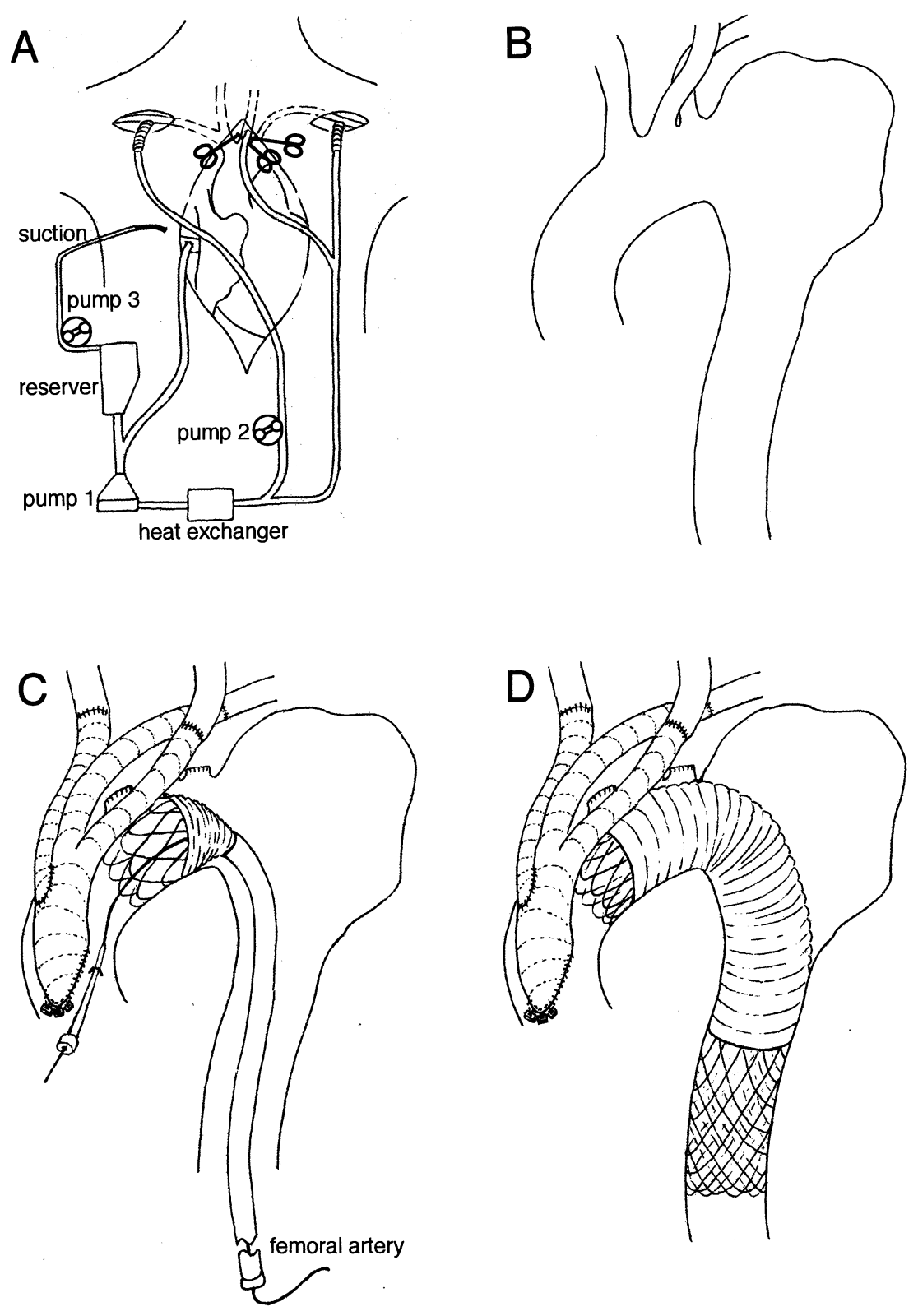

Figure 2. The assisted circulation is shown in part A. Left heart bypass was switched to SCP by placing clamps on 3 arch vessels. An extended aortic arch aneurysm (B) was treated with the custom-made MK stent graft (D) that was inserted into the aortic arch after extra-anatomic arch vessel bypass construction (C).

vessels were divided, and their stumps were closed with 5-0 monofilament sutures. A side-biting clamp was placed on the ascending aorta, and the proximal end of the $\mathrm{Y}$ graft was anastomosed to the aorta in end-to-side fashion by using 5-0 monofilament sutures. Subsequently, the side-biting clamp was removed, and the 3 outflow tracts of the Y graft were anastomosed to the 3 arch vessels, respectively, in end-to-end fashion (Figure 2, C). After weaning from SCP, protamine was administrated once to stop bleeding. A sufficient landing zone was prepared for the proximal side of the stent graft by means of this extra-anatomic bypass. After light reheparinization, a sheath $(5 \mathrm{~F})$ was inserted into the ascending aorta, a long guiding wire was inserted into the aorta through the sheath, and the wire was pulled out from the right femoral arterial conduit by using a snare catheter. The custommade MK stent graft with a maximum diameter of $40 \mathrm{~mm}$ was delivered into the aortic arch through the right femoral arterial conduit by a long sheath catheter (Figure 2, $C$ and $D$ ). Intraoperative angiography showed that the proximal end of the stent graft landed in the arch, the stent graft expanded and fit well to the wall, and no sign of the endoleak existed (Figure 1, B). Postoperative 
computed tomography showed that the size of the aneurysm was reduced. The patient's renal function recovered to preoperative levels after a transient use of hemodialysis. The patient was discharged from our hospital without blood-streaked sputum.

\section{Discussion}

The MK stent graft is a flexible, custom-made, curved stent graft. It usually takes a week until we receive the stent graft after placing an order. In this case the MK stent graft fit tightly to the 3-dimensional curvy portion of the aorta and did not cause kinking or endoleak at all. Although total replacement of the aortic arch would be one of the best solutions for the aortic arch aneurysm, this procedure is surgically stressful, especially for patients with complications. ${ }^{5}$ Advantages of endovascular stent graft delivery with extra-anatomic arch vessel bypass by SCP are relief from cardiac arrest, relief from circulatory arrest, and relief from use of an oxygenator. The preoperative creatinine clearance value of this patient was $18 \mathrm{~mL} / \mathrm{min}$, and the postoperative renal function recovered to preoperative levels after transient use of dialysis. This suggested that the level of surgical stress of this procedure was acceptable for this patient. SCP alone requires lower levels of heparinization than cardiopulmonary bypass because of the lack of an oxygenator. It is a big advantage of this procedure to prevent bleeding in a patient with such potential for massive lung bleeding. To reduce the risk of brain complications, we closed the arch vessels before the use of the side-biting clamp.

Endovascular delivery of the MK stent graft with extra-anatomic arch vessel bypass by using SCP could be a useful and minimally invasive therapeutic strategy for patients with aortic arch aneurysms who are considered at high surgical risk.

\section{References}

1. Dake MD, Miller DC, Mitchell RS, Semba CP, Moore KA, Sakai T. The "first generation" of endovascular stent-grafts for patients with aneurysms of the descending thoracic aorta. J Thorac Cardiovasc Surg. 1998;116:689-704.

2. Mitchell RS, Dake MD, Sembra CP, Fogarty TJ, Zarins CK, Liddel RP, et al. Endovascular stent-graft repair of thoracic aortic aneurysms. J Thorac Cardiovasc Surg. 1996;111:1054-62.

3. Orihashi K, Matsuura Y, Sueda T, Watari M, Okada K, Sugawara Y, et al. Echocardiography-assisted surgery in transaortic endovascular stent grafting: role of transesophageal echocardiography. J Thorac Cardiovasc Surg. 2000;120:672-8.

4. Kato M, Kaneko M, Kuratani T, Horiguchi K, Ikushima H, Ohnishi K. New operative method for distal aortic arch aneurysm: combined cervical branch bypass and endovascular stent-graft implantation. $J$ Thorac Cardiovasc Surg. 1999;117:832-4.

5. Coselli JS, Buket S, Djukanovic B. Aortic arch operation: current treatment and results. Ann Thorac Surg. 1995;59:19-27.

\title{
Does bridging to transplantation with a left ventricular assist device adversely affect posttransplantation survival? A comparative analysis of mechanical versus inotropic support
}

\author{
Jeffrey A. Morgan, MD, YooKyung Park, BS, Aftab R. Kherani, MD, Deon W. Vigilance, MD, Faisal H. Cheema, MD, \\ Mehmet C. Oz, MD, and Yoshifumi Naka, MD, PhD, New York, NY
}

I mplantation of a left ventricular assist device (LVAD) as a bridge to transplantation has become an acceptable intervention in patients with end-stage heart failure. ${ }^{1,2}$ Patients bridged to transplantation with LVADs have demonstrated improvements in blood pressure, hepatic function, renal function, physical function, and quality of life. ${ }^{3,4}$ However, whether mechanical support adversely affects posttransplantation survival is

\footnotetext{
From the Department of Surgery, Division of Cardiothoracic Surgery, College of Physicians and Surgeons, Columbia University, New York, NY.

Received for publication April 1, 2003; accepted for publication June 3, 2003.

Address for reprints: Yoshifumi Naka, MD, PhD, Columbia University, College of Physicians and Surgeons, 177 Fort Washington Ave, Milstein Hospital 7GN-435, New York, NY 10032 (E-mail: yn33@columbia.edu).

J Thorac Cardiovasc Surg 2003;126:1188-90

Copyright $\odot 2003$ by The American Association for Thoracic Surgery $0022-5223 / 2003 \$ 30.00+0$

doi:10.1016/S0022-5223(03)00935-8
}

still controversial. ${ }^{5}$ Do patients bridged to transplantation with an LVAD demonstrate decreased posttransplantation survival compared with patients bridged with inotropic support? The aim of this study was to answer this question.

\section{Patients and Methods}

We retrospectively reviewed our experience at Columbia Presbyterian Medical Center with bridge-to-transplantation patients from June 1996 through September 2002. During this time period, 266 patients in United Network for Organ Sharing status 1 were successfully bridged to transplantation by either mechanical ( $\mathrm{n}=$ $121,45.7 \%)$ or inotropic ( $\mathrm{n}=145,54.5 \%)$ support. LVAD support was provided by the HeartMate single-lead vented electric device (Thoratec, Pleasanton, Calif). Posttransplantation survival at 1, 3, and 5 years was evaluated in both groups.

Data were represented as frequency distributions and percentages. Values of continuous variables were expressed as means \pm SD. Continuous variables were compared by independent samples $t$ tests, whereas categorical variables were compared by $\chi^{2}$ tests. Kaplan-Meier analysis was used to calculate survival. Actuarial 